\title{
The Mayer Hashi Large-Scale Program to Increase Use of Long-Acting Reversible Contraceptives and Permanent Methods in Bangladesh: Explaining the Disappointing Results. An Outcome and Process Evaluation
}

\author{
Mizanur Rahman, ${ }^{a}$ M Moinuddin Haider, ${ }^{b}$ Sian L Curtis, ${ }^{a}$ Peter M Lance ${ }^{a}$
}

The Mayer Hashi program resulted in a modest increase in use of long-acting reversible contraceptives and permanent methods in Bangladesh, but less of an increase than in comparison nonprogram districts, which appears to have been the result of weaknesses in the health system environment in the program districts. Addressing system issues to support providers beyond training might have led to better results.

\section{ABSTRACT}

Background: Bangladesh has achieved a low total fertility rate of 2.3. Two-thirds of currently married women of reproductive age (CMWRA) want to limit fertility, and many women achieve their desired fertility before age 30 . The incidence of unintended pregnancy and pregnancy termination is high, however. Long-acting reversible contraceptives (LARCs), consisting of the intrauterine device and implant, and permanent methods (PM), including female sterilization and vasectomy, offer several advantages in this situation, but only $8 \%$ of CMWRA or $13 \%$ of method users use these methods. Program: The Mayer Hashi (MH) program (2009-2013) aimed to improve access to and the quality of LARC/PM services in 21 of the 64 districts in Bangladesh. It was grounded in the SEED (supply-enabling environment-demand) Programming Model. Supply improvements addressed provider knowledge and skills, system strengthening, and logistics. Creating an enabling environment involved holding workshops with local and community leaders, including religious leaders, to encourage them to help promote demand for LARCs and PMs and overcome cultural barriers. Demand promotion encompassed training of providers in counseling, distribution of behavior change communication materials in the community and in facilities, and community mobilization.

Methods: We selected $6 \mathrm{MH}$ program districts and 3 nonprogram districts to evaluate the program. We used a beforeafter and intervention-comparison design to measure the changes in key contraceptive behavior outcomes, and we used a difference-in-differences (DID) specification with comparison to the nonprogram districts to capture the impact of the program. In addition to the outcome evaluation, we considered intermediate indicators that measured the processes through which the interventions were expected to affect the use of LARCs and PMs.

Results: The use of LARCs/PMs among CMWRA increased between 2010 and 2013 in both program (from 5.3\% to $7.5 \%$ ) and nonprogram (from 5.0\% to $8.9 \%$ ) districts, but the rate of change was higher in the nonprogram districts. Client-provider interaction and exposure to LARCs/PMs were lower in the program than nonprogram districts, and the $\mathrm{MH}$ program districts had higher vacancies of key providers than the nonprogram areas, both indications of a more difficult health system environment.

Conclusion: The weaknesses in the health system in the MH districts apparently undermined the effectiveness of the program. More attention to system weaknesses, such as additional supportive supervision for providers, might have improved the outcome.

\footnotetext{
a University of North Carolina at Chapel Hill, Chapel Hill, NC, USA.

${ }^{b}$ International Center for Diarrhoeal Disease Research, Bangladesh, Dhaka, Bangladesh.

Correspondence to Mizanur Rahman (rahmanm@email.unc.edu).
}

\section{INTRODUCTION}

ong-acting and permanent methods of contra-
ception are components of a balanced method
mix. Long-acting reversible contraceptives (LARCs) 
comprise the intrauterine device (IUD) and implants, while permanent methods (PMs) include female sterilization and vasectomy. LARCs offer women and couples who wish to delay, space, or limit childbearing a number of advantages: they are highly effective, require little action on the part of the user, are suitable for a wide range of women, and are cost-effective over the long term. ${ }^{1,2}$ Discontinuation and failure rates are typically low, ${ }^{3}$ and LARCs have the potential to reduce unintended pregnancy and the associated risks of unsafe abortion and maternal morbidity and mortality. ${ }^{2,4}$ There is growing evidence that many women and couples prefer LARCs when they are available and affordable. ${ }^{5}$

Bangladesh has achieved a low level of fertility (total fertility rate of 2.3) and a contraceptive prevalence rate (CPR) of $62 \%$ among currently married women of reproductive age (CMWRA), increasing from about $20 \%$ in the early 1980s. ${ }^{6}$ Increased use of oral contraceptive pills and injectables largely accounts for the increase in CPR. Currently, only 13\% of users in Bangladesh rely on LARCs and PMs compared with $74 \%$ relying on pills, injectables, and condoms. ${ }^{6}$ Another $13 \%$ of users rely on traditional methods. Pill use increased dramatically from $3 \%$ in the 1980 s to $27 \%$ in 2014, while use of injectables increased from below $5 \%$ in the early 1990 s to $12 \%$ in $2014 .{ }^{6}$ In contrast, prevalence of PMs increased from 7\% in the early 1980 s to around $10 \%$ in the early 1990s, but has declined to 6\% in the 2000s. Among LARCs and PMs, tubectomy is the dominant method. IUD use is low, currently at $0.6 \%$ of CMWRA, and the current prevalence of implants is $1.7 \%$. The number of women choosing PMs decreased substantially beginning in the early 1990s, when the number of women relying on PMs who phased out of the reproductive ages annually was larger than the number of new acceptors, which led to a decrease in prevalence.

However, desire for fertility limitation has increased since the 1990s. For example, in the early 1980s, about half of mothers with 2 children wanted to have additional children. ${ }^{7}$ In 2011 , only $20 \%$ wanted to have additional children. ${ }^{8}$ Among all CMWRA, 58\% wanted to limit childbearing in 1993/1994, increasing to $65 \%$ in 2011 , and most women achieve their desired fertility before age $30 .{ }^{8}$ The high reliance on shortacting and traditional methods exposes women to increased risks of method failure ${ }^{10}$ and early method discontinuation ${ }^{11}$ during the 15 to 20 years when they could become pregnant after they achieve their desired family size. A high proportion of mothers $(30 \%)$ report that their last birth was unintended. ${ }^{8}$ Singh et al. reported there were 1.3 million menstrual regulations and abortions in 2010 in Bangladesh, yielding a pregnancy termination rate of 36 per 1,000 women ages 15-44 years old. ${ }^{12}$

The government of Bangladesh, along with NGOs, have encouraged efforts to increase use of LARCs and PMs to meet the needs of couples for sustained contraception. One example of these efforts is the Mayer Hashi (MH) program, funded by the United States Agency for International Development (USAID) from 2009 to 2013, to increase access to LARCs and PMs and improve the quality of services. We evaluated the impact of this program on use of LARCs and PMs and explored the pathways through which the program aimed to influence use of these methods to interpret the findings of the impact analysis.

\section{PROGRAM DESCRIPTION}

\section{Family Planning Service Delivery in Bangladesh}

Both the public and private sector deliver family planning services in Bangladesh. Most of the LARCs and PMs are provided by the public sector, whereas short-acting contraceptives are provided by both the public and private sector. In 2014, $92 \%$ of IUD users, $93 \%$ of implant users, $85 \%$ of vasectomy users, and $69 \%$ of female sterilization users obtained their method from the public sector. This compares with $42 \%$ of pill users, $61 \%$ of injectable users, and $15 \%$ of condom users. ${ }^{6}$ The Directorate General of Family Planning (DGFP) of the Ministry of Health and Family Welfare (MOHFW) is the public-sector agency that delivers both LARCs and PMs and short-acting contraceptives. Pills, condoms, and injectables are available at pharmacies, and pills and condoms are also available in convenience stores.

The DGFP delivers family planning services both in communities and health care facilities. Female family welfare assistants (FWAs) are responsible for visiting homes every 2 months to provide information and counseling and to supply pills and condoms. ${ }^{13}$ The family welfare visitor (FWV) provides injectables and IUDs at the family welfare center and satellite clinics in communities. In the past, only FWVs provided injectables, but FWAs have started to provide subsequent doses of injectables (the first dose is given by the FWV from a facility). There is

\section{Bangladesh has achieved a low total fertility rate of 2.3 and a contraceptive prevalence rate of $62 \%$.}


1 family welfare center and several satellite clinics in each union (the lowest-level administrative area) staffed by 1 FWV. The medical officer-maternal and child health (MO-MCH) provides implants, tubectomy, and no-scalpel vasectomy (NSV) from the upazila (subdistrict) health complex at the subdistrict headquarters. The MO-MCH or equivalent personnel also provide LARCs and PMs at other tertiary facilities throughout the country. The upazila family planning officer (UFPO) supervises community family planning activities. NGOs also offer family planning services at the community and facility levels in coordination with the DGFP. All service providers (FWA, FWV, and $\mathrm{MO}-\mathrm{MCH}$ ) receive training prior to beginning their jobs.

\section{The Mayer Hashi Program}

The Mayer Hashi The Mayer Hashi (MH) program operated in 21 of program operated the 64 districts in Bangladesh during the period in 21 of the 64 districts in Bangladesh during the period 2009-2013. delivery (available in some upazilas) - and the program began training private providers on LARCs and PMs.

The provider training focused on enhancing clinical knowledge and skills. FWVs received a 3-day clinical training on the IUD. The training specialists assessed the theoretical knowledge and reported technical skills of FWVs on the IUD prior to the training. The training was given in 2 stages: knowledge improvement and insertion practice. The trainers used discussions to address the knowledge gaps identified in the pre-training assessment. They demonstrated IUD insertion, and then the trainees practiced among clients inserting an IUD under the observation of the trainers, who provided immediate feedback. The MOs-MCH, resident medical officers, and OB/GYNs were given a 3-day clinical training on implant insertion, tubectomy, and NSV procedures following the same model as the FWV IUD training. The FWAs who counsel couples on contraceptive methods were trained on theoretical aspects of LARCs and PMs, such as the appropriateness of each method for a particular client situation, advantages and disadvantages of LARCs and PMs, and potential side effects.

To strengthen the systems supporting LARCs and PMs, managers were provided with a daylong LARC and PM orientation. The orientation covered the importance of LARCs and PMs in the family planning service delivery system, enhancing demand for LARCs and PMs, and improving systems to better support LARC and PM use. Throughout the program, managers received help in projecting their supply needs and ensuring a secure supply of equipment and commodities for LARCs and PMs.

\section{Supplies}

Supply improvement includes enhancement of provider knowledge and skills, systems strengthening, and logistics management. In addition to training DGFP providers and managers, the $\mathrm{MH}$ program trained resident medical officers of the Directorate General of Health Services, on LARCs and PMs. The Directorate General of Health Services is an MOHFW agency that provides preventive and curative health services. The $\mathrm{MH}$ program trained its resident medical officers to support expansion of LARC and PM services beyond the DGFP. The program also trained obstetrician/gynecologists (OB/GYNs) - the Directorate General of Health Services personnel who provide delivery services including cesarean

\section{Enabling Environment}

Creating an enabling environment included conducting workshops with local and community leaders, including religious leaders, to encourage their participation in demand promotion for LARCs and PMs and to help overcome cultural barriers. The program published Islam and Family Planning, a book in Bangla, and circulated it to religious leaders. The book explains that Islam supports birth spacing and describes the available birth-spacing methods, including LARCs. At the policy level, the MH program advocated policies to support expansion of LARC and PM services through the Directorate General of Health Services and the private sector. The technical assistance 


\section{BOX. Mayer Hashi Interventions}

The Mayer Hashi program was grounded in the SEED Programming Model, which encompasses Supply, Enabling Environment, and Demand interventions.

\section{Supply Improvement}

Enhancement of knowledge and skills of providers through training and refresher training of:

- FWAs

- FWVs (3-day clinical training on providing the IUD)

- $\mathrm{MOs}-\mathrm{MCH}$ (3-day clinical training on implant insertion, female sterilization, and no-scalpel vasectomy)

Expansion of services through the DGHS through training of:

- $R M O s$ and $O B / G Y N s$ (3-day clinical training on implant insertion, female sterilization, and no-scalpel vasectomy) System strengthening:

- Orientation of program managers (UFPOs and UHFPOs ) (1-day training on LARCs and PMs)

Logistics projection and management (also impacts the enabling environment):

- Technical assistance for program managers

Facilitation of policy formulation and policy change (also impacts the enabling environment):

- LARCs and PMs delivered through the DGHS

- LARCs and PMs available through the private sector

\section{Enabling Environment}

\section{Advocacy:}

- Orientation of community leaders and influential persons

\section{Demand Creation}

Community mobilization:

- Home visits by FWAs

- Courtyard meetings

- Cultural programs (e.g., street drama, music)

- Advocacy by local leaders and influential persons

Distribution of BCC materials (billboards, posters, and leaflets):

- In communities

- At facilities

Enhancement of provider skills:

- Training all providers in interpersonal communication

Abbreviations: BCC, behavior change communication; DGHS; Directorate General of Health Services; FWAs, family welfare assistants; FWVs, family welfare visitors; LARCs, long-acting reversible contraceptives; $M O s-M C H$; medical officers-maternal and child health; OB/GYNs, obstetrician/gynecologists; PMs, permanent methods; RMOs, resident medical officers; SEED, supply-enabling environment-demand; UFPO, upazila (subdistrict) family planning officer; UHFPO, upazila health and family planning officer. 
provided to managers to support planning for supplies described above also aimed to contribute to strengthening the enabling environment for LARCs and PMs by improving logistics systems.

\section{Demand Promotion}

Demand promotion encompassed training of providers in interpersonal communication, distributing behavior change communication (BCC) materials at the community and facility levels, and community mobilization. The program trained community- and facility-based providers on interpersonal communication techniques in a 1.5-day training session. The primary audience for the interpersonal communication training were the FWAs who counsel clients for LARCs and PMs at the community level, as well as other providers (FWVs, MOs-MCH). The providers were given BCC materials (flip charts and leaflets) on LARCs and PMs for client counseling. Leaflets on contraceptive methods were also produced for distribution to current and potential clients. Posters and billboards on LARCs and PMs were produced and displayed in facilities and communities.

FWAs organized community mobilization for LARCs and PMs through home visits and courtyard meetings. The primary audience for community mobilization were CMWRA. Street drama and music programs publicized LARCs and PMs, and local leaders and influential persons spoke to communities about LARCs and PMs.

The MH team routinely monitored the program by examining quarterly trends in LARC/PM acceptance in the MH intervention districts. However, there was no systematic plan for following up with providers after the training, either by the MH team or by the DGFP, to see how the training affected practice. USAID sponsored a midterm performance evaluation of the $\mathrm{MH}$ program that included comparing project achievements with expected results in intervention areas and interviewing stakeholders about program implementation. ${ }^{15}$

\footnotetext{
To measure impact METHODS: EVALUATION DESIGN on use of LARCs/ PMs, we used a before-after and interventioncomparison design, and a differencein-differences We used 2 approaches for the evaluation. To measure the impact of the $\mathrm{MH}$ interventions on use of LARCs and PMs, we used a before-after and intervention-comparison design. This design measures the changes in the key contraceptive behavior outcomes in the $\mathrm{MH}$ intervention areas relative to those in the comparison areas. ${ }^{16} \mathrm{We}$ used a difference-in-differences (DID) specifica(DID) specification. tion to capture the impact of the program. ${ }^{19}$ The
}

DID approach assumes that the change in the outcomes in the comparison group provides a good estimate of the change that would have occurred in the intervention group in the absence of the program. ${ }^{20,21}$ Under these assumptions, if the improvements in outcomes are significantly greater in the program areas compared with the comparison (nonprogram) areas, then we can conclude that improvements in outcomes were caused by the program.

To explore the pathways through which the $\mathrm{MH}$ interventions aimed to change contraceptive behaviors, we used an endline-only interventioncomparison design. In this design, we considered a series of intermediate indicators that measure the processes through which we expected the interventions to affect use of LARCs and PMs. This analysis is primarily descriptive.

\section{Data}

USAID requested the impact evaluation toward the end of the MH program. Therefore, it was not possible to collect pre-program data designed for the impact evaluation. This is a common problem in evaluation in practice. To overcome this problem, we used data from the 2010 Bangladesh Maternal Mortality Survey (BMMS 2010). ${ }^{22}$ The BMMS 2010 was a national survey conducted during January-August 2010. Although the MH program formally began in October 2009, implementation did not begin until March 2010 and was in a sufficiently preliminary state through the end of BMMS 2010 fieldwork that it was unlikely to have an impact on population-level use of LARCs or PMs before that time.

To form program and comparison samples for the evaluation, we randomly selected 6 (of 21) program districts (Barisal, Patuakhali, Comilla, Cox's Bazar, Moulvibazar, Sunamganj), and we selected 3 nonprogram districts (Kishoreganj, Mymensingh, Narsingdi) to match the program districts in initial LARC and PM prevalence. ${ }^{16}$ The nonprogram districts are from a different administrative division, but they are adjacent to some of the MH program districts, separated by a river. There is a cluster of districts in Dhaka, Chittagong, and Sylhet divisions that share a common characteristic of low performance in family planning and maternal and child health. ${ }^{16}$ The 3 comparison districts are in that cluster. Program districts received $\mathrm{MH}$ interventions to improve accessibility to and quality of LARC and PM services in addition to regular DGFP services, while nonprogram 


\begin{tabular}{|c|c|c|c|c|}
\hline \multirow[b]{2}{*}{ Survey and Respondents } & \multicolumn{2}{|c|}{ Program Districts $^{a}$} & \multicolumn{2}{|c|}{ Nonprogram Districts ${ }^{b}$} \\
\hline & Number & Response Rate (\%) & Number & Response Rate (\%) \\
\hline \multicolumn{5}{|l|}{ Household survey of CMWRA } \\
\hline Baseline - 2010 (BMMS) & 22,145 & $93^{c}$ & 9,893 & $93^{c}$ \\
\hline Endline - 2013 (MH Program) & 3,894 & $95^{d}$ & 1,970 & $93^{d}$ \\
\hline \multicolumn{5}{|l|}{ Provider survey, 2013} \\
\hline FWAs & 118 & 100 & 62 & 100 \\
\hline FWVs & 118 & 98 & 62 & 98 \\
\hline UFPOs & 59 & 71 & 31 & 83 \\
\hline $\mathrm{MOs}-\mathrm{MCH}$ & 59 & 32 & 31 & 61 \\
\hline RMOs & 53 & 79 & 28 & 79 \\
\hline OB/GYNs & 53 & 34 & 28 & 36 \\
\hline All providers & 460 & 77 & 242 & 82 \\
\hline \multicolumn{5}{|c|}{$\begin{array}{l}\text { Abbreviations: BMMS, Bangladesh Maternal Mortality Survey; CMWRA, currently married women of reproductive age; } \\
\text { FWAs, family welfare assistants; FWVs, family welfare visitors; MH, Mayer Hashi; MOs-MCH, medical officers-maternal } \\
\text { and child health; OB/GYNs, obstetrician/gynecologists; RMOs, resident medical officers; UFPOs, upazila (subdistrict) family } \\
\text { planning officers. } \\
\text { a Barisal, Patuakhali, Comilla, Cox's Bazaar, Moulvibazar, Sunamganj. } \\
\text { b Kishoregani, Mymensingh, Narsingdi. } \\
\text { c } 93 \% \text { for program and nonprogram districts together. } \\
\text { d 94\% for program and nonprogram districts together. }\end{array}$} \\
\hline
\end{tabular}

districts continued to receive regular DGFP services. This design is geared toward identification of the average effect of treatment on the treated.

The baseline data came from the BMMS 2010. The sample size in BMMS 2010 for the 6 program districts was 22,145 CMWRA, and for the 3 nonprogram districts, 9,893 CMWRA (Table 1). The endline household survey was conducted during February-May 2013 in the 9 study districts. The endline survey was a population-based household survey with a multistage sampling procedure. All CMWRA ages 13-49 who were usual residents in each selected household were eligible for the interview. The response rate for selected CMWRA was $93.4 \%$, yielding a sample of 5,864 CMWRA $(3,894$ in program districts and 1,970 in nonprogram districts).

Additionally, the endline data collection included a survey of 702 providers in the 9 districts (460 in program districts and 242 in nonprogram districts; Table 1). The public-sector service providers of the 90 upazilas in the 6 program and 3 nonprogram districts were the population of interest for the provider survey. For the DGFP in an upazila, there is $1 \mathrm{MO}-\mathrm{MCH}$ and $1 \mathrm{UFPO}$, both of whom were included in the survey. There are 6 to 8 unions per upazila, and each of the unions has 1 FWV and 6 FWAs. We selected 2 unions at random per upazila. Within the selected union, the lone FWV and 1 randomly selected FWA were interviewed. Providers from the Directorate General of Health Services were also interviewed for each of the upazilas: the resident medical officer and the OB/GYN. The overall response rate of service providers was $77 \%$ in the program districts and $82 \%$ in the nonprogram districts. The response rates were low for MOs-MCH and $\mathrm{OB} / \mathrm{GYNs}$ (32\%-36\% except for MOs-MCH in nonprogram areas, whose response rate was $61 \%$ ), primarily due to high vacancy rates for these positions. The provider survey included a module on BCC products and materials available at the facilities 
where the providers were interviewed. Data from providers are available only at endline.

\section{Indicators}

The outcome indicators considered in the women's data are:

- Use of LARCs and PMs

- Use of other methods

We also considered the following program exposure indicators for women:

- Client-worker contact at home

- Client-worker contact for health care at facilities

- Client-worker contact for health and family planning care at facilities

- Acceptors of temporary methods told about PMs

- Acceptors of injectables, the IUD, and implant told about method side effects

- Acceptors of injectables, the IUD, and implant told about follow-up visits

- Women who sought care from facilities who noticed messages on LARCs/PMs

- Women who heard, saw, or read messages about tubectomy

- Women who heard, saw, or read messages about NSV

- Women who heard, saw, or read messages about the IUD

- Women who heard, saw, or read messages about implants

- Women who heard, saw, or read messages about LARCs/PMs

- Women who heard, saw, or read messages about PMs

The BMMS 2010 includes only the indicators on use of LARCs/PMs and other methods, so the DID analysis is restricted to these outcomes only. Use of LARCs/PMs is the main outcome indicator that the MH program aimed to affect. The other indicators can be compared only between intervention and comparison areas at endline.

From the provider data, we considered a number of indicators related to:

- Provider training (program exposure)

- Provider knowledge and reported practice (level of adherence to pre- and post-counseling protocols associated with LARC/PM service provision)

- Pre-procedure counseling during provision of implants

- Post-procedure counseling when providing IUDs

○ Post-procedure counseling when providing tubectomy

- Information provided on method side effects

- Presence and use of BCC materials

\section{Analysis and Modeling}

To assess and contextualize program impact, we performed both bivariate and multivariate analyses. The bivariate analysis compared the indicators of interest between program and nonprogram districts and between 2010 and 2013 (when available). The multivariable analyses involved a regression model designed to assess impact. The foundation of the impact model was a DID regression specification. We implemented this specification through a multinomial logit regression model in which the dependent variable represented the choice of the contraceptive methods by CMWRA. Three categories of choice were considered: (1) no contraception, (2) LARC or PM (IUD, implant, tubectomy, or NSV), or (3) other methods (pill, injectable, condom, or traditional methods).

To implement the DID specification to capture the potential impact of the $\mathrm{MH}$ program on increased use of LARCs and PMs or other methods over time, we included dummy terms for whether the district was among the 6 selected for the program as well as a dummy variable indicating whether the observation came from the baseline (BMMS 2010) or follow-up (MH endline survey). We also included an interaction term between these 2 variables, which is crucial. Finally, the specification applied to the multinomial model also included selected independent variables, such as women's age, education, religion, household wealth quintile, and residential location (rural vs. urban).

We estimated the multinomial model in a fashion that recognizes the 3 sampling design features of the 2 surveys: stratification (both involved a stratified design), clustering, and sampling weights. To generate a unified weighting scheme between the 2 surveys, we normalized together the design selection probabilities for the observations 
from the 2 surveys. This, combined with the dummy variable indicating the survey (BMMS 2010 or MH endline) from which the observations were drawn, should control for any structural differences between the 2 surveys.

Because the multinomial logit is a nonlinear regression model, program impact was captured through an interaction effect obtained from the estimated model. Specifically, program impact on LARC/PM use was:

$$
\begin{gathered}
\operatorname{Pr}(\text { LARCPM }=1 \mid P=1, T=1, X) \\
-\operatorname{Pr}(\text { LARCPM }=1 \mid P=1, T=0, X) \\
-(\operatorname{Pr}(\text { LARCPM }=1 \mid P=0, T=1, X) \\
-\operatorname{Pr}(\text { LARCPM }=1 \mid P=0, T=0, X))
\end{gathered}
$$

where $\operatorname{Pr}(L A R C P M \mid P, T, X)$ is the predicted probability (from the fitted multinomial model) of using LARCs/PMs conditional on whether the individual resides in a program area $(P=1$ if residing in a program area and 0 otherwise), $T$ is an indicator for whether the observation is drawn from the baseline (BMMS 2010) or endline sample, and $X$ are the other characteristics (e.g., age, education) for which we controlled in the multinomial regression model. Program impact was thus the difference in predicted probabilities over time in program areas minus the same in nonprogram areas. This is in line with the classic DID approach to program impact estimation. The standard error of this program impact measure was obtained via the Delta method for functions of maximum likelihood estimates.

Beyond this causal modeling, all the indicators except for the use of LARCs/PMs and other methods were compared between program and nonprogram districts only at endline. This helped us to understand the intermediate-level variables through which the program can affect LARC/PM use.

\section{Additional Analysis}

Bangladesh has regional variations in use of health and family planning services. ${ }^{8}$ Most of the $\mathrm{MH}$ districts (17 of 21) come from the eastern region, which tends to have weaker health systems and more conservative values. Therefore, we also examined selected indicators by region within program areas and included some health system indicators obtained from DGFP records. The additional health system indicators included vacancy level for MOs-MCH, vacancy level for UFPOs, client-provider contact, and client exposure to BCC materials. Most of these health system indicators refer to 2013, either from the endline survey or from government records. The vacancy rates of MOs-MCH and UFPOs refer to the year 2013, and we assume that the rates remained the same during 2010-2013. This assumption is plausible because the DGFP did not recruit for MO-MCH or UFPO positions during this period, ${ }^{23}$ and therefore no change in vacancy is expected. The vacancy level could be changed through transfer of personnel, but this is unlikely because of the way the system operates.

\section{RESULTS \\ Background Characteristics of Sampled Women}

The LARC and PM use rates in program and nonprogram samples were comparable in 2010 (i.e., at baseline). We also found that these rates were comparable for program and nonprogram districts in 2004 and 2007 for the years when data were available. Women's age, number of children, and education were comparable in program and nonprogram districts, but the nonprogram areas were more urban and had a smaller non-Muslim population than the selected program districts (Table 2). The BMMS over-sampled urban areas, while the endline MH survey did not. Estimates representative of the populations of the 9 districts considered in this study are straightforward for both surveys through the application of appropriate sampling weights.

\section{Provider Training}

In the program districts, $63 \%$ of each group of providers, MOs-MCH, FWVs, and FWAs, reported that they received training on LARCs and PMs compared with $42 \%$ of MOs-MCH, $23 \%$ of FWVs, and $15 \%$ of FWAs in the nonprogram districts. Among OB/GYNs and resident medical officers, $28 \%$ and $5 \%$, respectively, reported receiving training on LARCs and PMs in the program districts compared with none in nonprogram districts.

\section{Provider Knowledge, Skills, and Practice} Almost all the MOs-MCH and FWAs reported that they explained to clients the advantages and disadvantages of implants (Table 3). We also asked providers whether they ensured informed choice ("ensure that the client made her decision after having full information"). A higher
Most of the Mayer Hashi districts (17 of 21) were in the eastern region of Bangladesh, which tends to have weaker health systems and more conservative values. 
TABLE 2. Background Characteristics of Sampled Women

\begin{tabular}{lrrrrr}
\hline & \multicolumn{2}{c}{ Program Districts } & & \multicolumn{2}{c}{ Nonprogram Districts } \\
\cline { 2 - 3 } \cline { 6 - 6 } & $\mathbf{2 0 1 0}$ & $\mathbf{2 0 1 3}$ & & $\mathbf{2 0 1 0}$ & $\mathbf{2 0 1 3}$ \\
\hline Age, years, mean & 30.6 & 31.4 & & 30.3 & 31.5 \\
No. of children, mean & 2.6 & 2.7 & & 2.5 & 2.6 \\
No education, \% & 31.1 & 28.5 & & 36.7 & 32.0 \\
Lowest 2 quintiles, \% & 39.9 & 42.3 & & 40.7 & 35.6 \\
Non-Muslim, \% & 13.7 & 10.4 & & 5.7 & 3.5 \\
Urban, \% & 33.5 & 25.6 & & 44.3 & 27.0 \\
\hline
\end{tabular}

Source of data: 2010 baseline data are from the Bangladesh Maternal Mortality Survey; 2013 endline data are from the Mayer Hashi endline survey.

percentage of MOs-MCH (37\%) and FWAs (39\%) than FWVs $(14 \%)$ replied in the affirmative to this question for implants in the program districts. This percentage was lower $(26 \%$ for MOs-MCHs, 23\% for FWA, and 7\% for FWVs) in the nonprogram districts.

For IUD clients, in program districts, $74 \%$ of FWVs (the only IUD provider) said they provide the follow-up card to the clients, and $54 \%$ of FWAs, who accompany the clients for the procedure and play an important role in enhancing the client-provider interaction, said they provide the follow-up card (Table 3). The follow-up card for IUD clients is an important tool for identifying method complications and their treatment, and it is expected to lead to higher continuation of the method. A higher percentage of both FWVs and FWAs reported providing the follow-up card in nonprogram districts than program districts-for FWVs, $90 \%$ vs. $74 \%(P \leq .05)$ and for FWAs, $73 \%$ vs. $54 \%(P \leq .05)$.

Similar patterns emerged for female sterilization clients. The level of reported knowledge and adherence of reported provider practice to standard protocols (e.g., the pre- and post-counseling protocols) was (a) generally low in both the program and nonprogram districts and (b) statistically similar in the 2 areas. However, the percentage of providing the follow-up card by FWVs was significantly greater $(P \leq .01)$ in nonprogram districts than program districts (Table 3). Reported practice was better among higher-level providers, such as MOs-MCH, than among FWVs and FWAs in nonprogram areas, and for some indicators in program areas.

\section{BCC Materials at Facilities}

BCC materials were commonly available in the facilities in program districts: $86 \%$ to $92 \%$ of facilities had billboards, banners, or posters on LARCs/ PMs in and around the facilities (Figure 1). Such BCC materials were also commonly available in nonprogram district facilities, but less so $(74 \%$ to $82 \%$ of facilities). Just over one-half of the program district facilities had a recognizable place where clients could see leaflets and booklets on LARCs/PMs, compared with only $2 \%$ in the nonprogram districts. In $88 \%$ of facilities in program districts, the providers had job aids to provide information to clients and to counsel clients on LARCs/PMs, compared with $77 \%$ in nonprogram districts $(P \leq .05)$.

\section{Client-Provider Contact}

In 2013, $13 \%$ of women interviewed in the household survey reported they were visited by family planning workers in the last 3 months in program districts, compared with $23 \%$ in nonprogram districts (Table 4). The level of clientworker contact was low in both types of districts, and it is significantly lower $(P \leq .001)$ in the program districts than nonprogram districts. The CMWRA also had significantly higher contacts with service providers at facilities in nonprogram districts than in program districts.

\section{Information Through Service Providers or Facilities}

Quality of care of family planning services can be enhanced if contraceptive clients are told 
TABLE 3. Provider Practice (\%) at Endline, Mayer Hashi Provider Survey, 2013

\begin{tabular}{|c|c|c|c|c|c|c|}
\hline & \multicolumn{2}{|c|}{ FWAs } & \multicolumn{2}{|c|}{ FWVs } & \multicolumn{2}{|c|}{ MOs-MCH } \\
\hline & $\begin{array}{l}\text { Program } \\
(\mathrm{n}=118)\end{array}$ & $\begin{array}{c}\text { Nonprogram } \\
(n=62)\end{array}$ & $\begin{array}{l}\text { Program } \\
(n=116)\end{array}$ & $\begin{array}{c}\text { Nonprogram } \\
(n=61)\end{array}$ & $\begin{array}{c}\text { Program } \\
(n=19)\end{array}$ & $\begin{array}{l}\text { Nonprogram } \\
(n=19)\end{array}$ \\
\hline \multicolumn{7}{|l|}{ Pre-counseling for implant clients } \\
\hline $\begin{array}{l}\text { Explain advantages and disadvantages of } \\
\text { implants }\end{array}$ & 97 & 98 & 31 & 23 & 95 & 100 \\
\hline Ensure informed choice & 39 & 23 & 14 & 7 & 37 & 26 \\
\hline \multicolumn{7}{|l|}{ Mention probable side effects of implants } \\
\hline Amenorrhea & 64 & 81 & 22 & 20 & 68 & 100 \\
\hline Spotting & 47 & 58 & 22 & 11 & 74 & 95 \\
\hline \multicolumn{7}{|l|}{ Post-counseling for IUD clients } \\
\hline Provide the follow-up card & 54 & 73 & 74 & 90 & 58 & 95 \\
\hline $\begin{array}{l}\text { Determine that clients understand key } \\
\text { counseling points }\end{array}$ & 31 & 8 & 9 & 10 & 21 & 16 \\
\hline \multicolumn{7}{|l|}{ Post-counseling for female sterilization clients } \\
\hline Provide the follow-up card & 53 & 68 & 66 & 87 & 58 & 95 \\
\hline $\begin{array}{l}\text { Determine that clients understand key } \\
\text { counseling points }\end{array}$ & 9 & 3 & 8 & 15 & 21 & 26 \\
\hline
\end{tabular}

about method side effects, are reminded about follow-up visits, and are told about other method options. ${ }^{24}$ The percentages were less than $50 \%$ for all indictors related to these aspects of quality of care, and most of the differences between program and nonprogram districts in 2013 were not significant (Table 4). For example, only $40 \%$ and $33 \%$ of temporary method acceptors were told about permanent methods in program and nonprogram districts, respectively. Further, 38\% and $49 \%$ of injectable, implant, and IUD acceptors reported they were told about method side effects in the program and nonprogram districts, respectively. Only $31 \%$ and $48 \%$ of injectable, implant and IUD acceptors were reminded about followup visits in program and nonprogram districts, respectively, and the difference between program and nonprogram districts was significant.

\section{Exposure to BCC Materials on LARCs/PMs}

In the program districts, $15 \%$ of women reported that they read, heard, or saw messages on the
IUD in the 3 months before the survey, $22 \%$ on implants, $29 \%$ on tubectomy, and $17 \%$ on NSV (Table 4). Women in nonprogram districts were significantly more likely to recall hearing, seeing, or reading messages on all LARCs and PMs except NSV.

\section{LARC/PM and Other Method Use}

Use of LARCs/PMs among CMWRA increased between 2010 and 2013 in both program (from $5.3 \%$ to $7.5 \%$ ) and nonprogram (from $5.0 \%$ to Use of LARCs/PMs $8.9 \%$ ) districts, but the increase was significantly increased lower in program than nonprogram districts between 2010 (Figure 2). Table 5 compares the method-specific rates between program and nonprogram districts and between 2010 (baseline) and 2013 (endline). Among the LARCs/PMs, tubectomy was the most commonly used method at baseline, used by over $3 \%$ of CMWRA in 2010. Use of other LARCs/ PMs was between $0.4 \%$ and $0.8 \%$ at baseline. There was an increase in the use of each method between 2010 and 2013 in program and nonprogram and 2013 in both program and nonprogram districts, but the increase was significantly lower in program districts. 
FIGURE 1. Percentage of Facilities Having BCC Materials/Products on LARCs/PMs at Endline, Mayer Hashi Provider Survey, 2013

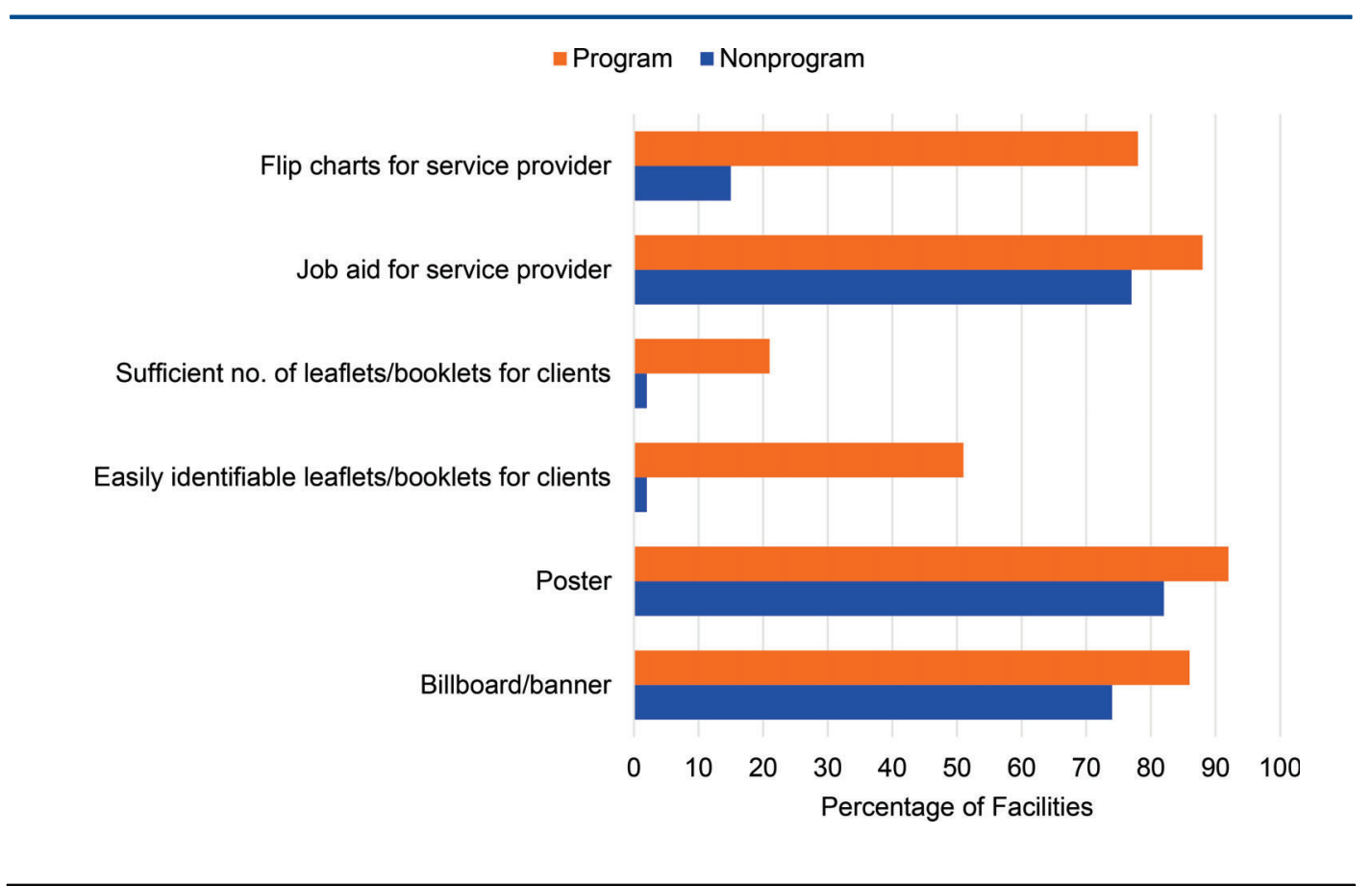

Abbreviations: BCC, behavior change communication; LARCs, long-acting reversible contraceptives; PMs, permanent methods.

districts, except for the IUD in program districts, where use declined from $0.5 \%$ to $0.4 \%(P \leq .01)$. The increase in method use was higher in nonprogram districts than program districts, except for NSV.

The CPR increased by 1.6 percentage points (from $54.2 \%$ to $55.8 \%$ ) in 6 program districts and by 3.5 percentage points (from $58.7 \%$ to $62.2 \%$ ) in 3 nonprogram districts. This means that most of the increase in the CPR was due to an increase in use of LARCs/PMs in both areas. Figure 2 confirms that use of other methods besides LARCs/ PMs either declined or was unchanged in both program and nonprogram districts.

\section{Multivariate Analysis}

Table 6 shows the multinomial logit estimates of coefficients for use of LARCs/PMs and other methods. For LARCs/PMs, program impact (which, as discussed in the Methods, is captured by the interaction effect estimated from the predicted probabilities of using LARCs/PMs obtained from the multinomial logit model for each combination of program area and survey wave) is -0.017 and not significant $(P=.14)$. Thus, we find that the program did not have any significant effect on increasing the probability of CMWRA using LARCs/PMs.

\section{Regional Variation and Health System Context} As noted previously, MH program districts were predominantly located in the eastern region of Bangladesh which tends to have weaker health systems and more conservative values. To explore the role of health system and regional context on our findings, Table 7 presents selected indicators of health system context alongside changes in the LARC/PM use observed for subregions within program and nonprogram districts. Characteristics of a stronger health system context include (1) low vacancies of MOs-MCH and UFPOs, (2) high level of client-provider contact, and (3) high level of LARC/PM information dissemination. Nonprogram districts performed better 
TABLE 4. Women's Reports of Client-Provider Contact, Informed Choice, and Exposure to Information on LARCs/PMs, Mayer Hashi Household Survey, 2013

\begin{tabular}{|c|c|c|c|c|c|}
\hline & \multicolumn{2}{|c|}{ Percentage } & \multicolumn{2}{|c|}{ Sample Size } & \multirow[b]{2}{*}{$P$ Value } \\
\hline & Program & Nonprogram & Program & Nonprogram & \\
\hline \multicolumn{6}{|l|}{ Provider contact with CMWRA (in last 3 months) } \\
\hline Visited by family planning workers & 13 & 23 & 3,194 & 1,637 & $<.001$ \\
\hline Sought health care from government facilities & 30 & 44 & 3,117 & 1,544 & $<.001$ \\
\hline $\begin{array}{l}\text { Sought health or family planning care from government } \\
\text { facilities }\end{array}$ & 44 & 55 & 3,117 & 1,544 & $<.001$ \\
\hline \multicolumn{6}{|c|}{ Informed choice - Received family planning or LARC/PM information from providers or facilities (in last 3 months) } \\
\hline Temporary method acceptors who were told about PMs & 40 & 33 & 410 & 174 & NS \\
\hline $\begin{array}{l}\text { Injectable, IUD, and implant acceptors who were told } \\
\text { about side effects }\end{array}$ & 38 & 49 & 216 & 79 & NS \\
\hline $\begin{array}{l}\text { Injectable, IUD, and implant acceptors who were } \\
\text { reminded about follow-up visits }\end{array}$ & 31 & 48 & 216 & 79 & $<.05$ \\
\hline $\begin{array}{l}\text { CMWRA who sought health or family planning care } \\
\text { and noticed BCC materials with LARC/PM messages }\end{array}$ & 42 & 43 & 1,369 & 854 & NS \\
\hline \multicolumn{6}{|c|}{ Exposure to LARC/PM Information - Heard, saw, or read messages ${ }^{a}$ (in last 3 months) about: } \\
\hline IUDs & 15 & 21 & 3,194 & 1,637 & $<.001$ \\
\hline Implants & 22 & 40 & 3,194 & 1,637 & $<.001$ \\
\hline Tubectomy & 29 & 35 & 3,194 & 1,637 & $<.001$ \\
\hline No-scalpel vasectomy & 17 & 13 & 3,194 & 1,637 & $<.001$ \\
\hline LARCs/PMs & 38 & 50 & 3,194 & 1,637 & $<.001$ \\
\hline PMs & 31 & 35 & 3,194 & 1,637 & $<.001$ \\
\hline \multicolumn{6}{|c|}{$\begin{array}{l}\text { Abbreviations: BCC, behavior change communication; CMWRA, currently married women of reproductive age; IUD, intrauterine device; LARCs, } \\
\text { long-acting reversible contraceptives; PMs, permanent method; NS, not significant. } \\
\text { a From TV, radio, newspaper/magazine, billboard/poster, folk song/theater, courtyard meeting, health/family planning worker, health facility, } \\
\text { or friend/relative. }\end{array}$} \\
\hline
\end{tabular}

than program districts (both eastern and southcentral regions) on all of these indicators. There was little difference between eastern and southcentral program areas; the program areas in the eastern region had lower vacancies of UFPOs than the south-central program areas but higher vacancies for MOs-MCH, and fewer women visited health facilities for care than in the south-central program districts, which provides fewer opportunities for client-provider interactions. Therefore, it appears that the $\mathrm{MH}$ interventions were in districts with weaker health systems. However, the increase in use of LARCs/PMs in the south-central program districts was only slightly lower than in the nonprogram districts (located in the north-central region), while LARC/ PM use lagged behind in program districts in the eastern region, suggesting that regional factors beyond the health system context may also be important.

\section{DISCUSSION}

The primary objective of this evaluation study was to estimate the impact of the Mayer Hashi 
FIGURE 2. Use of LARCs/PMs and Other Methods, by Program vs. Nonprogram Districts, 2010 and 2013, Mayer Hashi Evaluation
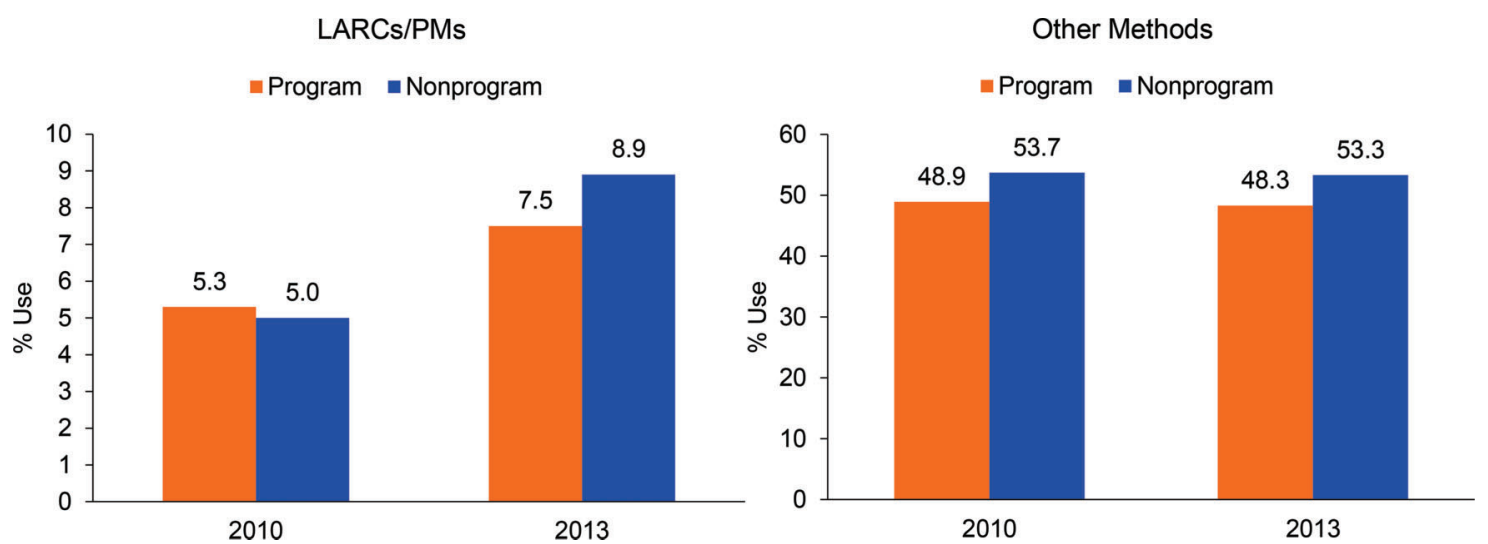

Abbreviations: LARCs, long-acting reversible contraceptives; PMs, permanent methods.

The lack of impact of the Mayer Hashi interventions on LARC/PM use at the population level could be related to structural constraints associated with program/service readiness. program on use of LARCs and PMs in the program areas. Additionally, we explored descriptively the intermediate outcomes through which the program aimed to influence use of LARCs and PMs to interpret the findings of the impact analysis. Our findings show that the coverage of service provider training was higher in program than nonprogram districts, but higher training coverage did not necessarily translate into better provider knowledge or reported practice. Service providers in program districts were more aware of policy changes or of new policies than providers in nonprogram districts, but reported practices hardly differed between the 2 types of districts. BCC materials on LARCs and PMs were more commonly found in facilities in program districts than in nonprogram districts, but CMWRA were more likely to recall seeing, hearing, or reading messages on LARCs and PMs in nonprogram districts. The use of LARCs/PMs increased between 2010 and 2013 in both types of districts, but the rate of change was not greater in the program than the nonprogram districts.

One reason suggested for the underutilization of LARCs/PMs in many low- and middle-income countries is that these methods are more challenging for the health system to deliver than short-acting methods. ${ }^{2,5}$ Our analysis suggests that the Mayer Hashi program districts were programmatically less "ready" than nonprogram districts to provide
LARCs and PMs. Notably, program districts had a higher rate of vacancy of $\mathrm{MOs}-\mathrm{MCH}$, the only provider of implants and female and male sterilization, than nonprogram districts. Also, vacancy of UFPOs, the upazila (subdistrict) family planning manager who supervises family planning outreach activities, was higher in the program than nonprogram districts.

The government monitoring and supervision system is also weak. The ongoing monitoring and supervision of the trained providers was the responsibility of the government of Bangladesh and not in the scope of the Mayer Hashi program, which resulted in weaknesses in support for translation of knowledge and skills acquired in training into behavior change. The providers did not receive any mentoring or supportive supervision, a crucial element of performance improvement. Moreover, LARC/PM service delivery requires carefully designed activities to deal with quality of care, clients' conservative outlook in the program districts, and many other challenges. The program districts, with poor program readiness and other problems, had an increase in LARC/ PM use of 2 percentage points, compared with 4 percentage points in the nonprogram districts. This increase of 2 percentage points is considerable in view of all the challenges in the program districts. CMWRA in program districts reported less contact with the health system than women 
TABLE 5. Change in LARC/PM Method Use Among CMWRA Between 2010 and 2013, Mayer Hashi Program

\begin{tabular}{|c|c|c|c|}
\hline & \multicolumn{3}{|c|}{$\%$ Reporting Use } \\
\hline & 2010 & 2013 & Change \\
\hline \multicolumn{4}{|l|}{ IUD } \\
\hline Program & 0.5 & 0.4 & -0.1 \\
\hline Nonprogram & 0.4 & 0.6 & 0.2 \\
\hline \multicolumn{4}{|l|}{ Implant } \\
\hline Program & 0.7 & 1.2 & 0.5 \\
\hline Nonprogram & 0.8 & 1.9 & 1.1 \\
\hline \multicolumn{4}{|l|}{ Tubectomy } \\
\hline Program & 3.7 & 4.9 & 1.2 \\
\hline Nonprogram & 3.2 & 5.7 & 2.5 \\
\hline \multicolumn{4}{|l|}{ NSV } \\
\hline Program & 0.4 & 1.0 & 0.6 \\
\hline Nonprogram & 0.5 & 0.8 & 0.3 \\
\hline \multicolumn{4}{|l|}{ Any LARC/PM } \\
\hline Program & 5.3 & 7.5 & 2.1 \\
\hline Nonprogram & 5.0 & 8.9 & 4.0 \\
\hline
\end{tabular}

in nonprogram districts. Family planning workers' home visits and visits by women to heath facilities for family planning or other care were both higher in the nonprogram districts.

Some interventions were undertaken at the policy level to influence the enabling environment. In particular, policy-level work was successful in expanding provision of LARCs and PMs to include the Directorate General of Health Services and private/NGO providers, and the project began training these providers too. These larger system changes will likely take time to affect the health system environment substantially, however.

Because of the generally lower desire for fertility limitation and weaker health systems in the eastern region where the Mayer Hashi districts were largely located, it may be more appropriate to focus on increasing use of short-acting methods in the immediate future. In contrast, the western region has an environment that is likely to be more conducive to LARC/PM promotion because of the higher desire for fertility limitation and higher use of contraception there, and the region's stronger family planning program infrastructure.

The $\mathrm{MH}$ team routinely examined quarterly trends in LARC/PM acceptance in the $\mathrm{MH}$ districts. These analyses of routine service statistics indicated that LARC/PM use was increasing and that the project was exceeding its objectives. ${ }^{15}$ The lack of impact of the project becomes apparent when the increase in LARC/PM use in program districts is compared with the increase in nonprogram districts. Such an analysis is beyond the scope of most project monitoring plans, but this illustrates the limitations of relying primarily on monitoring service statistics in program areas to track progress toward objectives.

There is a relatively long series of intermediate steps from the project interventions to the outcome of increased LARC/PM use at the population level. The midterm evaluation commissioned by USAID identified some limitations in intermediate steps (e.g., BCC activities) from key informant interviews and site visits. The evaluation noted that providers who were trained in postpartum IUD insertion had little opportunity to apply those skills because postpartum women were not strongly motivated to accept IUDs. ${ }^{15}$ Such implementation insights are helpful. However, as noted previously, there was no systematic plan for following up with providers to assess the effect of training on practice, or for monitoring other intermediate steps in the program. Increased attention to process evaluation to complement outcome monitoring and impact evaluation can identify interventions that are effective and those that are ineffective, and inform corrections to the program. ${ }^{25}$

\section{Limitations}

This article reports on an evaluation of a program operating at scale under real-world conditions. Such evaluations face a number of design and implementation challenges that require pragmatic and creative approaches. ${ }^{26,27}$ We faced a common challenge: the evaluation was requested toward the end of the project, so we could not collect baseline data specific to the evaluation. For example, it was not possible to ensure that the program and nonprogram districts had similar health system capacities.

\section{Because of the lower desire for fertility limitation and the weaker health systems in the eastern region of Bangladesh, it may be more appropriate to focus on increasing use of short-acting methods in the immediate future.}


TABLE 6. Multinomial Logit Coefficient Estimates and Estimated Program (Interaction) Effect for LARC/PM Use and Other Method Use, Mayer Hashi Evaluation, 2013 (N=37,902)

\begin{tabular}{|c|c|c|c|c|c|c|}
\hline & \multicolumn{3}{|c|}{ LARCs/PMs } & \multicolumn{3}{|c|}{ Other Methods } \\
\hline & Coefficient & SE & $P$ Value & Coefficient & SE & $P$ Value \\
\hline Program (ref: nonprogram) & -0.084 & 0.088 & .34 & -0.243 & 0.049 & $<.001$ \\
\hline Year 2013 (ref: 2010) & 0.616 & 0.157 & $<.001$ & 0.145 & 0.070 & .04 \\
\hline Program X Year & -0.359 & 0.182 & .05 & -0.223 & 0.093 & .02 \\
\hline \multicolumn{7}{|l|}{ Age, years (ref: 25-29) } \\
\hline$<20$ & -2.396 & 0.280 & $<.001$ & -0.812 & 0.072 & $<.001$ \\
\hline $20-24$ & -1.039 & 0.166 & $<.001$ & -0.283 & 0.056 & $<.001$ \\
\hline $30-34$ & 0.691 & 0.122 & $<.001$ & 0.247 & 0.072 & .001 \\
\hline $35-39$ & 1.071 & 0.127 & $<.001$ & 0.460 & 0.071 & $<.001$ \\
\hline $40-44$ & 0.487 & 0.155 & .002 & -0.054 & 0.078 & .49 \\
\hline $45-49$ & 0.169 & 0.157 & .28 & -1.269 & 0.081 & $<.001$ \\
\hline \multicolumn{7}{|l|}{ Education (ref: no education) } \\
\hline Primary incomplete & 0.242 & 0.110 & .03 & 0.189 & 0.057 & .001 \\
\hline Primary complete & -0.164 & 0.127 & .20 & 0.273 & 0.053 & $<.001$ \\
\hline Secondary incomplete & -0.276 & 0.140 & .05 & 0.231 & 0.061 & $<.001$ \\
\hline Secondary complete or higher & -0.589 & 0.197 & .003 & 0.279 & 0.085 & .001 \\
\hline \multicolumn{7}{|l|}{ Wealth quintile (ref: lowest) } \\
\hline Second & -0.207 & 0.115 & .07 & 0.064 & 0.056 & .25 \\
\hline Middle & -0.285 & 0.124 & .02 & -0.139 & 0.061 & .02 \\
\hline Fourth & -0.263 & 0.135 & .05 & -0.221 & 0.072 & .002 \\
\hline Highest & -0.380 & 0.171 & .03 & -0.378 & 0.083 & $<.001$ \\
\hline \multicolumn{7}{|l|}{ Religion (ref: Muslim) } \\
\hline Non-Muslim & 0.545 & 0.137 & $<.001$ & 0.278 & 0.063 & $<.001$ \\
\hline \multicolumn{7}{|l|}{ Sector (ref: rural) } \\
\hline Urban & 0.278 & 0.115 & .02 & 0.286 & 0.054 & $<.001$ \\
\hline Constant & -1.988 & 0.129 & $<.001$ & 0.380 & 0.073 & $<.001$ \\
\hline \multicolumn{7}{|l|}{ Program effect ${ }^{a}$} \\
\hline Interaction effect & -0.017 & 0.011 & .14 & -0.038 & 0.021 & .07 \\
\hline
\end{tabular}


TABLE 7. Indicators of Regional Health System Strength and Increase in LARC/PM Use, Mayer Hashi, 2013

\begin{tabular}{|c|c|c|c|}
\hline & \multicolumn{2}{|c|}{ Program Districts } & \multirow{2}{*}{$\frac{\text { Nonprogram Districts }}{\text { North-central region }}$} \\
\hline & Eastern region & South-central region & \\
\hline Vacancy of UFPO, \% & 36 & 47 & 10 \\
\hline Vacancy of $\mathrm{MO}-\mathrm{MCH}, \%$ & 56 & 38 & 19 \\
\hline $\begin{array}{l}\text { CMWRA visited by FWA and other family } \\
\text { planning worker, } \%\end{array}$ & 13 & 12 & 23 \\
\hline $\begin{array}{l}\text { CMWRA sought health/family planning } \\
\text { care from facilities, } \%\end{array}$ & 41 & 49 & 55 \\
\hline $\begin{array}{l}\text { CMWRA heard, saw, or read about } \\
\text { LARCs/PMs, \% }\end{array}$ & 38 & 37 & 50 \\
\hline $\begin{array}{l}\text { Increase in LARC/PM use between } 2010 \\
\text { and } 2013 \text {, percentage points }{ }^{b}\end{array}$ & 1.6 & 3.3 & 4.0 \\
\hline \multicolumn{4}{|c|}{$\begin{array}{l}\text { Abbreviations: CMWRA, currently married women of reproductive age; FWA, family welfare assistant; LARC, long-acting } \\
\text { reversible contraceptive; MO-MCH, medical officer-maternal and child health; PM, permanent method; UFPO, upazila } \\
\text { (subdistrict) family planning officer. } \\
\text { a Although FWAs are supposed to make home visits every } 2 \text { months, in practice less than } 20 \% \text { of CMWRA reported that they } \\
\text { were visited by a family planning worker in the } 6 \text { months prior to the } 2011 \text { Demographic and Health Survey. } \\
\text { b It was not possible to match the program and nonprogram districts in the health system characteristics that may affect } \\
\text { couples' LARC/PM use. }\end{array}$} \\
\hline
\end{tabular}

We did not have baseline data on provider knowledge and behavior or on women's knowledge of and attitudes toward LARCs and PMs. Therefore, our analysis of the intermediate outcomes through which the program aimed to influence use of LARCs and PMs is limited to a comparison between program and nonprogram districts at endline only and is therefore more descriptive. It is possible that provider knowledge and practice were weaker in program than in nonprogram districts at baseline, and that the interventions brought the providers in the program districts up to the level of those in nonprogram districts. However, the baseline use of LARCs/PMs was the same in program and nonprogram areas, so it does not appear that any baseline differences in provider knowledge and practice were associated with a difference in use of LARCs/PMs. Therefore, while we might be missing some effects of training on the intermediate step of provider knowledge and practice, it is unlikely that this limitation explains the lack of effect of the interventions on LARC/ PM use.

The DID estimation strategy to evaluate the program effect on LARC/PM use was the strongest evaluation design available to us. The DID model rests on the assumption that the change observed in the nonprogram districts is a proxy for the change that would have been observed in the program districts in the absence of the interventions. It is not possible to test this assumption directly, although trends in LARC/PM use appear to have been similar in program and nonprogram districts between 2004 and 2010 . This is a limitation of DID analyses in general, however.

\section{CONCLUSION AND RECOMMENDATIONS}

Use of LARCs and PMs is increasing slowly in Bangladesh, but the increase is greater in districts or regions where the health system is stronger or the desire for family limitation is stronger. Provider vacancy is universally a crucial factor in efforts to improve health services. The availability of appropriate, high-quality providers for LARCs and PMs has been a challenge in Bangladesh for many years in spite of its substantial progress in health care. ${ }^{23,28}$

An immediate solution to these challenges is unlikely; therefore, Bangladesh should seek 
alternative and/or supplemental avenues to provide high-quality LARC/PM services. The privatization of LARC and PM services is one option. The Bangladesh government has opened up LARC/ PM services to the private sector recently, and combined efforts of the public-, private-, and NGO sectors should be encouraged, especially in view of the recent growth of the private sector for family planning and other reproductive and child health services. ${ }^{6,29}$ Further operations research is needed to discover innovative, affordable, and effective interventions to improve LARC/PM service delivery within a constrained health system, and more attention to process evaluation will improve our understanding of implementation and progress along the program pathway to complement outcome monitoring and impact evaluations.

Acknowledgments: MEASURE Evaluation is funded by the U.S Agency for International Development (USAID) under Cooperative Agreement GHA-A-00-08-00003-00 and is implemented by the Carolina Population Center at the University of North Carolina at Chapel Hill, in association with Palladium Group, ICF International; John Snow, Inc.; Management Sciences for Health; and Tulane University. We are grateful to the Carolina Population Center (R24 HD050924) for general support. The cooperation of the Mayer Hashi team, led by Abu Jamil Faisel, in this evaluation work is appreciated. Kanta Jamil provided valuable comments on this evaluation. The opinions expressed in this article do not necessarily reflect the views of USAID or the United States government.

Competing Interests: None declared.

\section{REFERENCES}

1. Speidel JJ, Harper CC, Shields WC. The potential of long-acting reversible contraception to decrease unintended pregnancy. Contraception. 2008;78(3):197-200. CrossRef. Medline

2. Wickstrom J, Jacobstein R. Contraceptive security: incomplete without long-acting and permanent methods of family planning Stud Fam Plann. 2011;42(4):291-298. CrossRef. Medline

3. Staveteig S, Mallick L, Winter R. Uptake and discontinuation of long-acting reversible contraceptives (LARCs) in low-income countries. DHS Analytical Studies No. 54. Rockville (MD): ICF International; 2015. Available from: https://dhsprogram.com/ pubs/pdf/AS54/AS54.pdf

4. Hubacher D, Mavranezouli I, McGinn E. Unintended pregnancy in sub-Saharan Africa: magnitude of the problem and potential role of contraceptive implants to alleviate it. Contraception. 2008;78(1):73-78. CrossRef. Medline

5. Stunning popularity of LARCs with good access and quality: a major opportunity to meet family planning needs. Glob Health Sci Pract. 2015;3(1):12-13. CrossRef. Medline

6. National Institute of Population Research and Training (NIPORT); Mitra and Associates; ICF International. Bangladesh demographic and health survey 2014. Dhaka (Bangladesh): NIPORT; 2016. Co-published by Mitra and Associates and ICF International. Available from: https://dhsprogram.com/pubs/ $\mathrm{pdf} /$ FR311/FR311.pdf

7. Mitra SN, Kamal GM. Bangladesh contraceptive prevalence survey--1983. Final report. Dhaka (Bangladesh): Mitra and Associates; 1985
8. National Institute of Population and Research and Training (NIPORT); Mitra Associates; ORC Macro. Bangladesh demographic and health survey 2011. Dhaka (Bangladesh): NIPORT; 2013. Co-published by Mitra Associates and ORC Macro. Available from: http://dhsprogram.com/pubs/pdf/ fr265/fr265.pdf

9. STATcompiler [Internet]. Rockville (MD): ICF International. 1985 [cited 2016 May 31]. Available from: http://legacy. statcompiler.com/

10. Bairagi R, Rahman M. Contraceptive failure in Matlab, Bangladesh. Int Fam Plan Perspect. 1996;22(1):21-25. CrossRef

11. Curtis $S$, Evens E, Sambisa W. Contraceptive discontinuation and unintended pregnancy: an imperfect relationship. Int Perspect Sex Reprod Health. 2011;37(2):58-66. CrossRef. Medline

12. Singh S, Hossain A, Maddow-Zimet I, Bhuiyan HU, Vlassoff M, Hussain R. The incidence of menstrual regulation procedures and abortion in Bangladesh, 2010. Int Perspect Sex Reprod Health. 2012;38(3):122-132. CrossRef. Medline

13. Khuda B,Kane TT,Phillips JF, editors. Improving the Bangladesh Health and Family Planning Programme: lessons learned through operations research. Dhaka (Bangladesh): International Centre for Diarrhoeal Disease Research; 1997. Available from: http:// pdf.usaid.gov/pdf_docs/PNACL953.pdf

14. EngenderHealth. Baseline survey report, Mayer Hashi Project. Dhaka (Bangladesh): EngenderHealth; 2011.

15. United States Agency for International Development (USAID). Midterm performance evaluation of The Mayer Hashi Project: effective delivery of long-acting and permanent family planning methods and maternal health services in Bangladesh. Washington (DC): USAID; 2012. Available from: http://pdf usaid.gov/pdf_docs/pdact724.pdf

16. Rahman M, Curtis SL, Haider MM. Impact evaluation of the Mayer Hashi Program of long-acting and permanent methods of contraception in Bangladesh. Chapel Hill (NC): MEASURE Evaluation; 2014. Available from: http://www.cpc.unc.edu/ measure/resources/publications/tr-14-102

17. EngenderHealth. The SEED assessment guide for family planning programming. New York: EngenderHealth; 2011. Available from: http://www.engenderhealth.org/files/pubs/familyplanning/seed-model/seed-assessment-guide-for-familyplanning-programming-english.pdf

18. The RESPOND Project. Holistic approach enhances family planning programs: RESPOND's experience with the SEED Programming Model. New York: EngenderHealth, RESPOND Project; 2014. Available from: http://www.respond-project.org/ pages/files/6_pubs/project_briefs/Project-Brief-27-SEEDAugust2014.pdf

19. Angrist JD, Pischke J-S. Mostly harmless econometrics: an empiricist's companion. Princeton (NJ): Princeton University Press; 2009.

20. Meyer B. Natural and quasi-experiments in economics. J Bus Econ Stat. 1995;13(2):151-161. CrossRef

21. Lance P, Guilkey D, Hattori A, Angeles $G$. How do we know if a program made a difference? A guide to statistical methods for program impact evaluation. Chapel Hill (NC): MEASURE Evaluation; 2014. Available from: http://www.cpc.unc.edu/ measure/resources/publications/ms-14-87-en

22. National Institute of Population and Research and Training (NIPORT); MEASURE Evaluation; icddr,b. Bangladesh maternal mortality and health care survey 2010. Dhaka (Bangladesh): NIPORT; 2012. Co-published by MEASURE Evaluation and icddr,b. Available from: http://wnw.cpc.unc.edu/measure/resources/ publications/tr-12-87 
23. Ministry of Health and Family Welfare (MOHFW), Program Management and Monitoring Unit, Planning Cell. Mid-term program implementation report: July 2011-June 2014. Dhaka (Bangladesh): Ministry of Health and Family Welfare; 2014.

24. Koenig MA, Hossain MB, Whittaker $M$. The influence of quality of care upon contraceptive use in rural Bangladesh. Stud Fam Plann. 1997;28(4):278-289. CrossRef. Medline

25. Evans R, Scourfield J, Murphy S. Pragmatic, formative process evaluations of complex interventions and why we need more of them. J Epidemiol Community Health. 2015;69(10):925-926. CrossRef. Medline

26. Victora CG, Black RE, Boerma JT, Bryce J. Measuring impact in the Millennium Development Goal era and beyond: a new approach to large-scale effectiveness evaluations. Lancet. 2011;377(9759):85-95. CrossRef. Medline
27. Skiles MP, Hattori A, Curtis SL. Impact evaluations of large-scale public health interventions: experiences from the field. MEASURE Evaluation Working Paper 14-157. Chapel Hill (NC): MEASURE Evaluation; 2014. Available from: http://www.cpc.unc.edu/ measure/resources/publications/wp-14-157.

28. Ministry of Health and Family Welfare (MOHFW). Bangladesh health facility survey 2011. Dhaka (Bangladesh): MOHFW; 2012.

29. National Institute of Population Research and Training (NIPORT); International Centre for Diarrhoeal Disease Research, Bangladesh (icddr,b); MEASURE Evaluation. Bangladesh urban health survey 2013. Final report. Dhaka (Bangladesh): NIPORT; 2015. Co-published by icddr,b and MEASURE Evaluation. Available from: http://www.cpc.unc.edu/measure/resources/ publications/tr-15-117

\section{Peer Reviewed}

Received: 2015 Sep 30; Accepted: 2016 Jun 12

Cite this article as: Rahman M, Haider MM, Curtis SL, Lance PM. The Mayer Hashi large-scale program to increase use of long-acting reversible contraceptives and permanent methods in Bangladesh: explaining the disappointing results. An outcome and process evaluation. Glob Health Sci Pract. 2016;4 Suppl 2:S122-S139. http://dx.doi.org/10.9745/GHSP-D-15-00313.

(c) Rahman et al. This is an open-access article distributed under the terms of the Creative Commons Attribution License, which permits unrestricted use, distribution, and reproduction in any medium, provided the original author and source are properly cited. To view a copy of the license, visit $\mathrm{http}: / /$ creativecommons.org/licenses/by/3.0/. When linking to this article, please use the following permanent link: $\mathrm{http}: / / \mathrm{dx}$.doi.org/ 10.9745/GHSP-D-15-00313. 